\title{
AVALIAÇÃO DA SUSCEPTIBILIDADE DE SOLOS GNAISSICOS À EROSÃO SUBSUPERFICIAL
}

\section{Evaluation of piping erosion susceptibility in gnaissic soils}

Fernando Morais Professor Doutor do Centro Federal de Educação Tecnológica de Ouro Preto moraisgeographer@gmail.com Luis Almeida Prado Bacellar Professor Doutor do Departamento de Geologia da Universidade Federal de Ouro Preto luisapbacellar@gmail.com

Frederico Garcia Sobreira Professor Doutor da Universidade Federal de Ouro Preto sobreira@degeo.ufop.br

Artigo recebido para publicação em 28/03/2007 e aceito para publicação em 07/08/2007

RESUMO: As áreas com rochas do embasamento cristalino da bacia do rio Maracujá apresentam grande incidência de voçorocas de grandes dimensões. O presente trabalho objetivou investigar a influência dos processos erosivos subsuperficiais na evolução destas formas de erosão, além de compreender quais os fatores mineralógicos e texturais que poderiam influenciar na erodibilidade dos solos da bacia, especialmente dos saprolitos. Para tanto, foram realizados ensaios de caracterização básica e de avaliação da erodibilidade em amostras representativas, sendo o principal destes o ensaio de pin-hole, que avalia a suscetibilidade dos solos à erosão por piping e, com modificações, também por erosão por carreamento. Foram construídos em laboratório modelos físicos a fim de se observar estes e outros possíveis mecanismos de erosão atuantes nos taludes das voçorocas, especialmente os escorregamentos. Os resultados mostram que as voçorocas da bacia não sofrem influência significativa dos pipings em seu avanço, tendo em vista que estes só ocorrem na parte não saturada dos taludes das voçorocas, quando são formados pela ação da concentração de águas superficiais. Isto se dá porque os saprolitos colapsam quando saturados em função de sua baixa coesão, fazendo com que os pipings não se preservem. Por outro lado, as experiências com modelagem física e os dados de campo evidenciam que os saprolitos, quando saturados, instabilizam-se por meio de escorregamentos rotacionais (slumps), mesmo em taludes baixos e pouco íngremes.

Palavras-chaves: erodibilidade, piping, saprolitos, ensaio de pin-hole.

ABSTRACT: The basement rock areas of the Maracujá hydrographic basin show great incidence of huge gullies. This work aims to investigate the influence of the underground erosive processes in the evolution of these features and to understand how the mineralogical and textural factors could affect soil erodibility, specially of the saprolites, since the lateric soils of this basin are more resistant to erosion. So, basic characterization and erodibility essays were carried out in 
representative soil samples. Soil susceptibility to piping and seepage erosion were investigated through current and modified pin-hole-essays. Laboratory physical models were used in order to observe these and other possible underground erosion mechanisms, especially the slides. However, piping erosion only occurs in the unsaturated portion of gully slopes, provoked by the concentration of superficial water, since pipes are not stable under total saturation, when their roofs tend to collapse, because of the low cohesion of these saprolites. In the other hand, slumps are very common in the saturated portion of gullies, affecting saprolites even in small and low declivity slopes.

Keywords: erodibility, piping, saprolites, pin-hole-essays.

\section{INTRODUÇÃO}

Grande parte do território brasileiro se localiza em áreas de rochas graníticas e gnáissicas do embasamento cristalino. Na maioria destas áreas, o embasamento está recoberto por espessa capa de regolito, muito suscetível ao voçorocamento.

Por conta de sua grande área de ocorrência, as voçorocas constituem um dos principais tipos de risco geológico no Brasil. Embora ocorram naturalmente no tempo geológico, muitas destas voçorocas resultam de atividades antrópicas mal planejadas, como agricultura e urbanização.

A geração das voçorocas em áreas do embasamento pode se dar por processos de erosão superficial ou subsuperficial, mas sua evolução normalmente se acelera quando são atingidos os solos saprolíticos, que, no caso de rochas graníticas e gnáissicas, são normalmente muito mais erodíveis que os horizontes superficiais dos solos tropicais (solos lateríticos).

Porém, apesar de quase sempre mais alta que a dos solos superficiais, a erodibilidade dos solos saprolíticos pode variar, até mesmo dentro de uma mesma litologia, em função de sutis variações composicionais e texturais (Bacellar, 2000).

A diferença de erodibilidade entre os solos superficiais e os saprolíticos de rochas do embasamento é facilmente identificável no campo, por critérios visuais, bem como por ensaios laboratoriais clássicos, como o ensaio de Inderbitzen, dentre outros.

Em contrapartida, as pequenas diferenças de erodibilidade dos solos saprolíticos nem sempre são perceptíveis quando se utilizam métodos convencionais. Assim, neste trabalho pretendeu-se investigar quais são os melhores ensaios para detectar as diferenças de erodibildade dos solos saprolíticos de gnaisse bem como tentar compreender quais são as variáveis mineralógicas e texturais que influenciam neste comportamento diferencial.

\section{LOCALIZAÇÃO}

Para realização deste estudo foram coletados solos da região sul do complexo de rochas do embasamento cristalino (Complexo Bação), no interior do Quadrilátero Ferrífero, no centro-sul do estado de Minas Gerais (Figura 1). Neste complexo predominam as rochas gnáissicas com fino bandamento, com ocorrências secundárias de granitóides, ambas com composição predominantemente granodiorítica. $\mathrm{O}$ manto de intemperismo é normalmente muito espesso, alcançando até 50 metros de espessura. $\mathrm{O}$ saprolito, que apresenta espessuras de até 40 metros, tem composição silto-argilosa e é composto essencialmente por quartzo, feldspato variavelmente alterado para caolinita, illita e moscovita. 


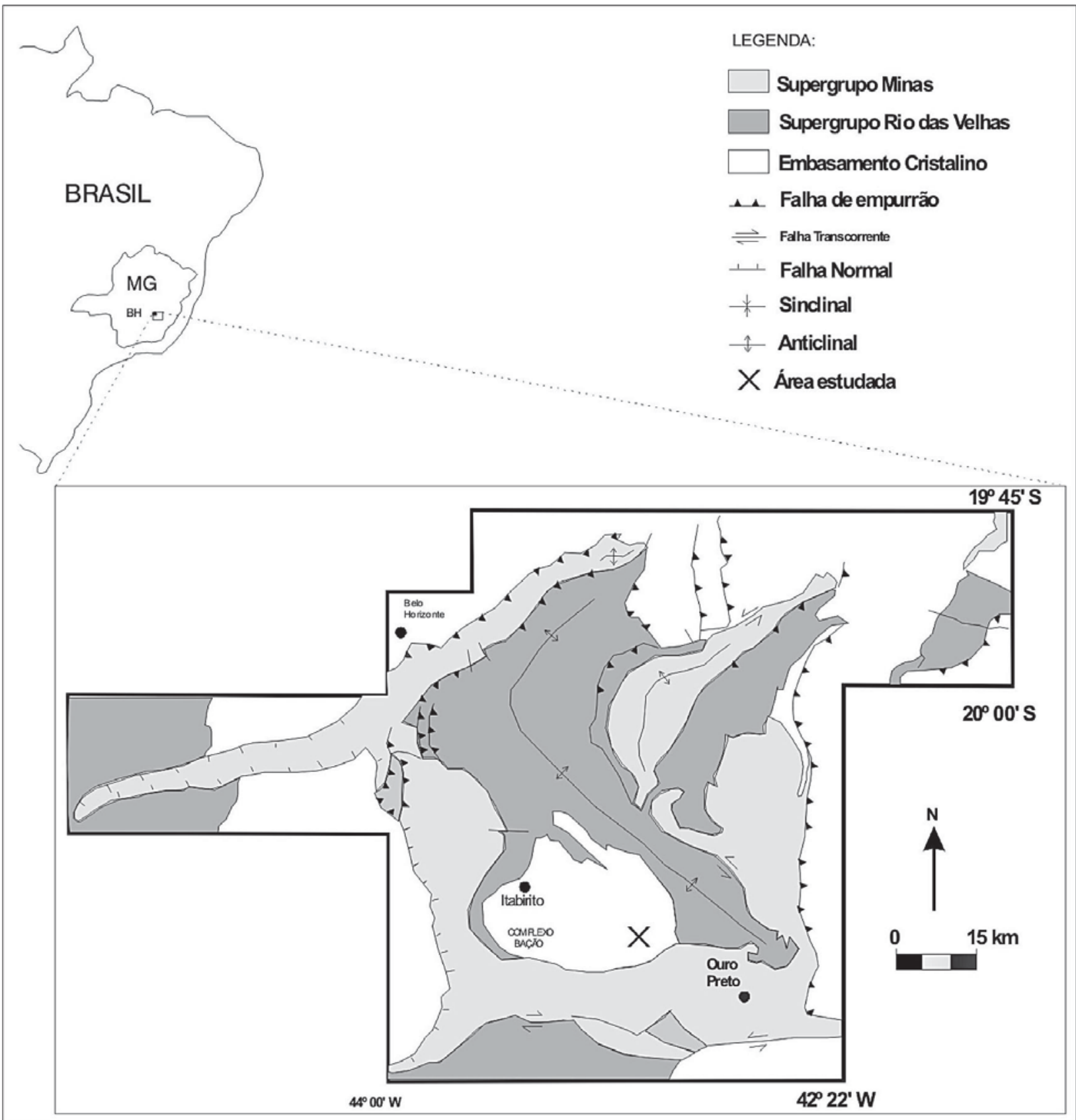

Figura 1. Localização da área escolhida para coleta de amostras de solos dentro do Complexo do Bação, Quadrilátero Ferrífero (MG). Adaptado de Bacellar (2000).

O solo laterítico sobrejacente (horizontes A e B) apresenta textura argilosa, possui de 1 a 10 metros de espessura, sendo composto predominantemente por caolinita, oxi-hidróxidos de ferro e alumínio e quartzo.

\section{METODOLOGIA}

Foram coletadas 9 amostras de saprolito e 1 amostra de solo laterítico para balizar os resultados.

Para a distinção de erodibilidade entre os saprolitos, o principal método adotado foi o ensaio de furo de agulha (pin-hole), seguindo a metodologia proposta por Sherard et al. (1976). Normatizado pela 
ABNT (NBR 14114/1998), constituiu-se o ensaio mais confiável para a identificar quantificar a dispersão (coloidal) e classificar os solos de textura fina quanto a sua dispersibilidade em água. Este ensaio consiste basicamente em percolar-se água através de um furo de agulha em um corpo de prova de solo indeformado a diferentes cargas hidráulicas $(50 \mathrm{~mm}$, $180 \mathrm{~mm}, 380 \mathrm{~mm}$ e $1020 \mathrm{~mm}$ ) e realizar leituras de vazão, observação da coloração do efluente e diâmetro final do orifício no corpo de prova.

Foram realizados também ensaios de granulometria (peneiramento e sedimentação) seguindo os procedimentos descritos pela ABNT (NBR 7181/1984);

Ensaio comparativo de dispersão SCS, normatizado pela ABNT (NBR 13602/1996). O que diferencia esse ensaio de uma análise granulométrica é a não utilização de agente dispersor além de não se utilizar agitador mecânico;

Estabilidade dos agregados, executado de acordo com os procedimentos elaborados pela EMBRAPA-CNPS (1997);

Penetração ao cone, proposto por Alcântara (1997) para determinar a erodibilidade, a partir do ensaio preconizado pela BS 1377/1975, esboçado por Head et. al. (1980), cujo objetivo original era a determinação do limite de liquidez do solo através de ensaio penetrométrico;

\section{Limite de liquidez (NBR 6459/1984);}

Ensaio de expansão livre, utilizado para determinar a expansão dos solos este método envolve os seguintes procedimentos: um solo seco ao ar livre é passado na peneira 10, colocando até o volume de $10 \mathrm{~mL}$ de uma proveta graduada de volume $100 \mathrm{~mL}$. Em seguida, adiciona-se este solo a uma segunda proveta contendo $50 \mathrm{~mL}$ de água destilada. Após 30 minutos de repouso, faz-se a leitura do volume (V) que este solo passou a preencher na proveta.

O índice de expansão livre é expresso em porcentagem e é determinado através do seguinte cálculo:

$$
\text { Expansão Livre }=\frac{\mathrm{V}-10}{10} \times 100 \%
$$

Ensaio de desagregação, normatizado pela ABNT (NBR 13601 e NBR 13602), os ensaios de desagregação realizados neste estudo seguiram os procedimentos descritos por Silva (2000), que consistem em moldar-se um corpo de prova cúbico com $6 \mathrm{~cm}$ de aresta e submetê-lo a diferentes níveis de inundação. Para observar os processos desencadeados pela amostra durante essa submersão.

A inundação das amostras dá-se em quatro estágios: no primeiro estágio coloca-se o cubo de solo sobre uma placa porosa dentro de uma bandeja. Coloca-se água destilada até a base da amostra, que permanece saturando por capilaridade por 30 minutos; no segundo estágio eleva-se o nível d'água até $1 / 3$ da altura da amostra e deixa-se por 15 minutos; no terceiro estágio esse nível passa para $2 / 3$ da amostra que fica parcialmente submersa por 15 minutos; no quarto e último estágio submerge-se totalmente a amostra que permanece neste grau de inundação por 24 horas.

Ao término dos ensaios foram feitos cruzamentos dos dados obtidos com investigações dos fatores mineralógicos, texturais e estruturais a fim de explicar o comportamento diferencial dos saprolitos de gnaisse à erosão subsuperficial e também encontrar a metodologia mais eficaz para a determinação da erodibilidade do solo.

Para reproduzir as diversas declividades do gradiente hidráulico, até a saturação máxima (fluxo paralelo ao da superfície do talude) foi idealizado um reservatório de água à montante, separado da caixa principal por uma placa acrílica co rasgos horizontais igualmente espaçados de $5 \mathrm{~cm}$. Assim como este reservatório possui um ladrão e como a saída da água é pela base da extremidade oposta da caixa, este gradiente pode ser controlado.

Foi construída uma caixa de acrílico (Figura 2), para a reprodução de modelos físicos de taludes 
das voçorocas, com $60 \mathrm{~cm}$ de comprimento, $40 \mathrm{~cm}$ de largura e $50 \mathrm{~cm}$ de altura com reservatório à montante da amostra para simulação em diversos gradientes hidráulicos. A exemplo de Rodrigues (1984), durante a aplicação desses gradientes, foram feitas observações de cunho qualitativo na tentativa de visualizar o desenvolvimento de processos que ocorrem nos sopés dos taludes das voçorocas. Para a reprodução dos taludes, utilizaram-se solos das mesmas áreas dos demais ensaios e as amostras foram coletadas em forma de blocos indeformados a fim de manter-se todas as características físicas do solo.

\section{Caixa de Modelagem Fisica}

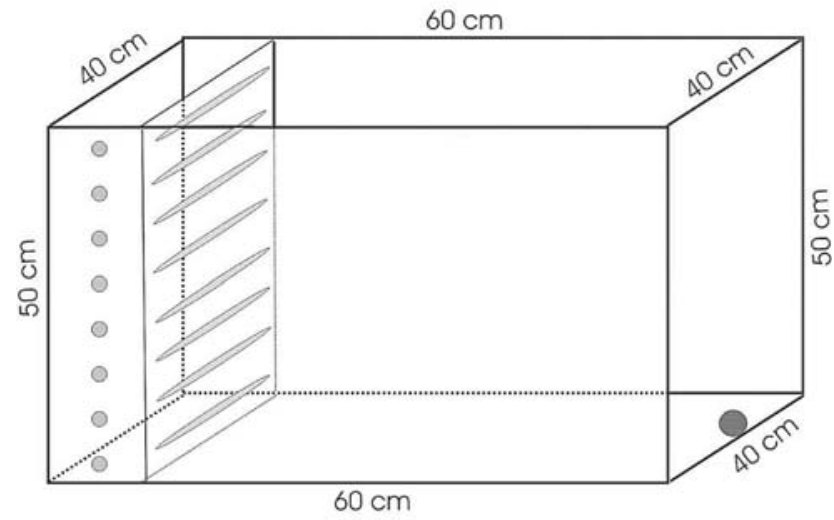

Ladrao com rosca, de 5 em $5 \mathrm{~cm}$

Figura 2. Caixa para modelagem de taludes.

\section{RESULTADOS E DISCUSSÃO}

Os ensaios granulométricos com defloculante mostraram resultados que corroboram os resultados encontrados por outros autores (Parzanese, 1991; Bacellar, 2000), que caracterizam os saprolitos das rochas do embasamento da bacia do rio Maracujá como silto-arenosos a areno-siltosos e os solos lateríticos como areno-argilosos.

Os resultados encontrados para a caracterização básica realizada para os solos estudados encontram-se dispostos na tabela 1 :

Tabela 1. Índices básicos de caracterização dos solos da bacia do Maracujá.

\begin{tabular}{c|c|c|c|c|c|c}
\hline Amostra & $\begin{array}{c}\text { Massa específica } \\
\text { natural }\left(\mathrm{g} / \mathrm{cm}^{3}\right)\end{array}$ & $\begin{array}{c}\text { Umidade } \\
(\%)\end{array}$ & $\begin{array}{c}\text { Massa dos grãos } \\
\text { específica }\left(\mathrm{g} / \mathrm{cm}^{3}\right)\end{array}$ & $\begin{array}{c}\text { Massa específica } \\
\text { aparente seca }\left(\mathrm{g} / \mathrm{cm}^{3}\right)\end{array}$ & $\begin{array}{c}\text { Índice } \\
\text { de vazios }\end{array}$ & $\begin{array}{c}\text { Porosidade } \\
(\%)\end{array}$ \\
\hline 01 & 1,77 & 13,7 & 2,34 & 1,56 & 0,50 & 33,0 \\
02 & 1,47 & 13,1 & 2,31 & 1,30 & 0,77 & 43,0 \\
03 & 1,63 & 18,8 & 2,35 & 1,38 & 0,70 & 41,0 \\
04 & 1,74 & 23,7 & 2,65 & 1,41 & 0,87 & 46,0 \\
05 & 1,60 & 16,1 & 2,54 & 1,37 & 0,85 & 45,0 \\
06 & 1,51 & 07,4 & 2,34 & 1,41 & 0,65 & 39,0 \\
07 & 1,81 & 22,0 & 2,62 & 1,48 & 0,77 & 43,0 \\
08 (solo laterítico) & 1,27 & 16,9 & 3,14 & 1,59 & 0,97 & 49,0 \\
09 & 1,53 & 09,3 & 2,41 & 1,40 & 0,72 & 41,0 \\
10 & 1,55 & 11,8 & 2,34 & 1,39 & 0,68 & 40,0 \\
\hline
\end{tabular}


Os resultados de limites de liquidez ilustram, além da diferença do solo laterítico para os saprolitos, uma variação neste índice de consistência entre os solos de mesma natureza, os saprolitos de gnaisse (Tabela 2).

Tabela 2. Resultados de limites de liquidez

\begin{tabular}{l|c|c|c|c|c|c|c|c|c|c}
\hline Amostra & 1 & 2 & 3 & 4 & 5 & 6 & 7 & 8 (solo laterítico) & 9 & 10 \\
\hline LL (\%) & 29,4 & 35,8 & 37,8 & 30,0 & 39,0 & 19,0 & 26,0 & 47,0 & 35,9 & 18,0 \\
\hline
\end{tabular}

Para os resultados de expansão livre com exceção da amostra 01, que apresentou índice de expansão livre de $18 \%$, as amostras de saprolito submetidas aos ensaios de expansão livre apresentaram índices variando entre 30\% e 40\% (Tabela 3). Para a amostra de solo laterítico (amostra 8) o índice de expansão livre foi de $20 \%$.

Tabela 3. Resultados de expansão livre

\begin{tabular}{l|c|c|c|c|c|c|c|c|c|c}
\hline Amostra & 1 & 2 & 3 & 4 & 5 & 6 & 7 & 8 (solo laterítico) & 9 & 10 \\
\hline Expansão (\%) & 18 & 30 & 35 & 35 & 30 & 40 & 39 & 20 & 30 & 40 \\
\hline
\end{tabular}

Assim como observado por Bacellar (2000) a penetração saturada constitui-se um bom índice para caracterizar sutis diferenças na erodibilidade de solos de mesma classe. Levando-se isto em consideração, é possível separar as amostras em três grupos quanto à resistência a penetração, sendo as amostras 1 e 8 mais resistentes à penetração, as amostras 7 , 2, 3, 5 e 9, de resistência média e as amostras 6, 10 e 4 apresentando baixa resistência (Tabela 4).

Tabela 4. Resultados dos ensaios de penetração ao cone.

\begin{tabular}{c|c|c|c}
\hline \multirow{2}{*}{ Amostras } & \multicolumn{2}{|c}{ Ensaio de penetração ao cone } \\
\cline { 2 - 4 } & Psat. $(\mathrm{mm})$ & Pnat.(mm) & DP (\%) \\
\hline 01 & 4,47 & 3,99 & 12,03 \\
02 & 11,09 & 5,13 & 123,18 \\
03 & 11,16 & 5,00 & 197,23 \\
04 & 12,87 & 4,33 & 97,11 \\
05 & 11,59 & 5,88 & 221,07 \\
06 & 17,37 & 5,41 & 82,12 \\
07 & 10,49 & 5,76 & 141,67 \\
08 (solo laterítico) & 5,51 & 2,28 & 122,78 \\
09 & 10,56 & 4,74 & 202,01 \\
\hline
\end{tabular}

Os ensaios de desagregação apresentaram resultados que corroboram os obtidos por Silva (2000) e classificam as amostras como desagregáveis por abatimento e dispersão. Estes ensaios permitem separar as amostras em três graus quanto à desagregabilidade (Tabela 5). 
Tabela 5. Agrupamento dos solos ensaiados quanto a desagregabilidade.

\begin{tabular}{l|c}
\hline Grau de desagregabilidade & Amostras \\
\hline Desagregam-se até o $2^{\circ}$ estágio & $2,3,4,5,6$ e 10 \\
Desagregam-se no $3^{\circ}$ estágio & 1,7 e 9 \\
Não desagregável & 8 (solo laterítico) \\
\hline
\end{tabular}

Os resultados pin-hole confirmaram a resistência dos solos lateríticos à erosão e definiram dois grupos de saprolitos quanto a dispersibilidade, que avalia a susceptibilidade dos solos a erosão por piping. A tabela 6 mostra a classificação destes solos quanto a dispersibilidade.

Tabela 6. Classificação dos solos ensaiados quanto a dispersibilidade, obtida através do ensaio de pin-hole.

\begin{tabular}{|c|c|c|c|c|c|c|c|c|c|c|}
\hline Amostra & 01 & 02 & 03 & 04 & 05 & 06 & 07 & 08 & 09 & 10 \\
\hline Dispersibilidade & ND1 & ND2 & $\begin{array}{l}\text { ND1- } \\
\text { ND2 }\end{array}$ & $\begin{array}{l}\text { ND1- } \\
\text { ND2 }\end{array}$ & D2 & ND3 & $\begin{array}{l}\text { ND1- } \\
\text { ND2 }\end{array}$ & ND1 & $\begin{array}{l}\text { ND1- } \\
\text { ND2 }\end{array}$ & ND3 \\
\hline \multicolumn{11}{|l|}{ D2 - Dispersivo } \\
\hline \multicolumn{11}{|c|}{ ND1 - Não Dispersivo } \\
\hline \multicolumn{11}{|c|}{ ND2 - Incipientemente Dispersivo } \\
\hline \multicolumn{11}{|c|}{ ND3 - Levemente Dispersivo } \\
\hline
\end{tabular}

Para os ensaios com modelos físicos foram construídos taludes de saprolito 30 a $50 \mathrm{~cm}$ de comprimento e $30 \mathrm{~cm}$ de altura, com inclinações variando de 20 a $40^{\circ}$. No decorrer dos ensaios, não se verificou o desenvolvimento de erosão por carreamento nem por piping, mesmo com a utilização fluxo paralelo à superfície do talude. Porém, depois de algumas horas começaram a aparecer algumas trincas de tração na superfície do talude, que resultaram na formação de escorregamentos rotacionais (slumps). Foram construídas artificialmente descontinuidades cilíndricas no sopé destes taludes, com solo totalmente saturado, para simular a possível evolução dos pipings. Sob condições saturadas, estes pipings não evoluíram, pois colapsaram totalmente, o que demonstra que este tipo de feição não se mantém preservado nestes saprolitos saturados.

Os resultados também permitem individualizar a existência de quatro grupos de solos saprolíticos com erodibilidades diferentes:
A - Solos pouco suscetíveis ao piping e aos escorregamentos (amostra 8 - solo laterítico):

$\sqrt{ }$ alta resistência a penetração ao cone

$\sqrt{ }$ baixo teor de silte, em ensaios sem defloculante; e alto teor de argila com defloculante;

$\sqrt{ }$ baixa expansibilidade, inferior a $22 \%$;

$\sqrt{ }$ baixa erodibilidade no ensaio de pinhole;

$\sqrt{ }$ desagregabilidade nula a baixa;

B - Solos pouco suscetíveis ao piping, mas suscetível a escorregamento (amostra 1):

$\sqrt{ }$ alta resistência a penetração ao cone;

$\sqrt{ }$ baixo teor de silte em ensaios sem defloculante;

$\sqrt{ }$ baixa expansibilidade, inferior a $20 \%$;

$\sqrt{ }$ baixa erodibilidade no ensaio pin-hole;

$\sqrt{ }$ desagregabilidade média; 
C - Solos medianamente suscetíveis ao piping e ao escorregamento (amostras 2, 3, 4, 7 e 9):

$\sqrt{ }$ média resistência a penetração ao cone; $\sqrt{ }$ teor intermediário de silte em ensaios sem defloculante (com exceção da amostra 9);

$\sqrt{ }$ expansibilidade, média

$\sqrt{ }$ erodibilidade média a baixa (amostra 7) no ensaio pin-hole;

$\sqrt{ }$ desagregabilidade média (amostra 9) a alta;

D - Solos muito suscetíveis ao piping e a escorregamento (amostras 5, 6 e 10):

$\sqrt{ }$ alto teor de silte em ensaios sem defloculante;

$\sqrt{ }$ resistência à penetração ao cone baixa

(amostras 6 e 10) a média (amostra 5);

$\sqrt{ }$ expansibilidade alta a média;

$\sqrt{ }$ média erodibilidade no ensaio pin-hole;

$\sqrt{ }$ desagregabilidade alta;

\section{CONCLUSÕES}

Os dados geotécnicos prévios foram confirmados; tendo-se em vista que, quase a totalidade dos dados obtidos neste trabalho corroboraram os dados anteriores.

Dados anteriores, confirmados pelos resultados da amostra 8 desta tese, mostram que os solos lateríticos são pouco erodíveis, em razão da forte agregação das partículas pelos óxidos e hidróxidos de ferro. Assim, a textura destes solos é argilosa quando se usa defloculante e agitação, e de areia grossa quando se efetuam ensaios granulométricos simulando condições naturais (SCS), ou seja, sem defloculante e agitação. Todos os ensaios realizados confirmaram essa maior resistência dos solos lateríticos à erosão;

As amostras coletadas confirmaram que os saprolitos são mais erodíveis que os solos lateríticos, mas apresentam erodibilidade desigual. Os dados indicam que a erodibilidade dos solos frente ao piping é maior nos de textura siltosa para ensaios sem defloculante e pobres em argilas.

Os ensaios de desagregação e com modelos físicos mostraram que os saprolitos são altamente instáveis a saturação e que os slumps são os maiores responsáveis pelo avanço das voçorocas, na zona de exfiltração.

Os pipings só foram vistos na porção não saturada dos taludes (segmento C), formados pela concentração do fluxo superficial durante as chuvas. Devido à saturação do solo, nas zonas de exfiltração do lençol freático (segmento D) estes pipings não se preservam, colapsando rapidamente devido à perda da sucção, como ficou bem claro nos ensaios de modelos físicos.

Nestes modelos, demonstrou-se que é impossível manter aberta uma descontinuidade de diâmetro de alguns milímetros com o solo saturado. Portanto, os pipings identificados nas porções não saturadas devem permanecer estáveis por causa da dificuldade de saturação.

Não ocorre a erosão por vazamento, devido à baixa permeabilidade destes solos.

\section{REFERÊNCIAS BIBLIOGRÁFICAS}

ASSOCIAÇÃO BRASILEIRA DE NORMAS TÉCNICAS. NBR 6459: Determinação do limite de liquidez. Rio de Janeiro, 1984. 6 p.

ASSOCIAÇÃO BRASILEIRA DE NORMAS TÉCNICAS. NBR 7181: Rio de Janeiro, Solo: análise granulométrica. Rio de Janeiro, 1984. 13 p.

ASSOCIAÇÃO BRASILEIRA DE NORMAS TÉCNICAS. NBR 13602. Solo - Avaliação da dispersibilidade de solos argilosos pelo ensaio sedimentométrico comparativo - Ensaio de dispersão SCS. Rio de Janeiro, 1996. 5 p.

ASSOCIAÇÃO BRASILEIRA DE NORMAS 
TÉCNICAS. NBR 14114. Solo - Solos Argilosos dispersivos. Identificação e classificação por meio do ensaio de furo de agulha (Pin-hole test). Rio de Janeiro, 1998. 8 p.

ALCÂNTARA, M.A.T. Aspectos geotécnicos da erodibilidade dos solos. 99 p. Dissertação de Mestrado, EESC/USP, São Carlos, 1997.

BACELLAR, L.A.P. Condicionantes Geológicos, Geomorfológicos e geotécnicos dos mecanismos de voçorocamento na bacia do Rio Maracujá, Ouro Preto, MG. 225 p. Tese de Doutorado COPPE/UFRJ, Rio de Janeiro, 2000.

DELGADO, L.O.B. Mapeamento geotécnico do distrito de Cachoeira do Campo, Ouro Preto - MG. Trabalho Geológico, UFOP/EM/DEGEO, Ouro Preto, 1991.

EMBRAPA-CNPS. Empresa Brasileira de Pesquisa Agropecuária - Centro Nacional de Pesquisa de Solos. Manual de métodos para análise de solo. Rio de Janeiro, $2^{\text {a }}$ ed. EMBRAPA-CNPS. 1997, 212 p.

HEAD, K.H. Manual of soil laboratory testing. v. 3, Pentech Press, London, 1986.

PARZANESE, G.A.C. Gênese e desenvolvimento das voçorocas em solos originados de rochas granitóides da região de Cachoeira do Campo, Minas Gerais. 117 p. Dissertação de Mestrado. UFV, Viçosa, 1991.

RODRIGUES, J.E. Estudo geotécnico dos fenômenos erosivos acelerados (boçorocas). In: Congr. Brás. Geol. Eng., 4,Belo Horizonte, Anais pp. 169182, 1984.

SANTOS, C.A. Comportamento Hidrológico Superficial, Subsuperficial e a Erodibilidade dos solos da região de Santo Antônio do Leite, distrito de Ouro Preto - MG. 108 p. Dissertação de Mestrado, UFOP/ EM/DEGEO, Ouro Preto, 2001.

SHERARD, J.L., DUNNIGAN, L.P., DECKER, R.S. Pinhole test for identifying dispersive soils. Jour- nal of the Geotechnical Engineering Division, Proceedings, American Society of Civil Engineers, v. 102, pp. 69-85. 1976.

SILVA, T.R.M. Caracterização e erodibilidade dos solos de uma voçoroca na região de Ouro Preto MG. 2000. 106 p. Dissertação de Mestrado, PECCOPPE/UFRJ, Rio de Janeiro, 2000. 